\title{
Study on How to Effectively Extract Bamboo Fibers from Raw Bamboo and Wastewater Treatment
}

\author{
Nguyen Tien Phong \\ Graduate Student, Doshisha University \\ Kyotonabe-City, Kyoto 610-0394, Japan \\ Tel: 81-080-413-38120 E-mail: etk1306@mail14.doshisha.ac.jp
}

Toru Fujii

Department of Mechanical Engineering and Systems, Doshisha University

Kyotonabe-City, Kyoto 610-0394, Japan

Tel: 81-090-819-00412Ｅ-mail: tfujii@mail.doshisha.ac.jp

Bui Chuong

Polymer Center, Hanoi University of Technology

No 1, Dai Co Viet, Hanoi, Vietnam

Tel: 84-090-344-6055 E-mail: buichuong-pc@mail.hut.edu.vn

Kazuya Okubo

Department of Mechanical Engineering and Systems, Doshisha University

Kyotonabe-City, Kyoto 610-0394, Japan

Tel: 81-774-656-444Ｅ-mail: kokubo@mail.doshisha.ac.jp

Received: August 3, 2011 Accepted: August 23, $2011 \quad$ Published: January 1, 2012

doi:10.5539/jmsr.vln1p144 URL: http://dx.doi.org/10.5539/jmsr.vln1p144

\begin{abstract}
Bamboo fibers are focused as one of substitution for natural plant fibers having many advantages such as low cost, low density, ecologically friendly, sustainability and biodegradability. The purpose of this study is to develop methods extracting bamboo fibers by using mechanical extracting, steam-explosion and alkaline-treatment techniques. How to control $\mathrm{pH}$ of wastewater yielding from alkali treatment is also one of the primary objectives of the present study. Mechanical properties (tensile strength, maximum strain at failure and Young's modulus) of extracted bamboo fibers were measured as well as their microstructure configuration. Interfacial strengths were tested between bamboo fibers and typical resins for polymer matrix composites such as unsaturated polyester and polypropylene. The variation of moisture absorption due to the difference of fiber extraction process was also determined. The experimental results proved that the alkaline-treatment was better than the steam-explosion method to extract bamboo fibers as well for mechanically extracted fibers as reinforcement for green composites, where two years or older raw bamboo (younger than four years old) was immersed in $1 \% \mathrm{NaOH}$ solution for 10 hours. The present study also revealed that $\mathrm{CO}_{2}$ gas was applicable to reduce $\mathrm{pH}$ from 10.8 to 7.0 within 110 minutes by aeration.
\end{abstract}

Keywords: Bamboo; Bamboo fibers; Wastewater; Alkaline treatment; Steam explosion; Mechanical extraction, $\mathrm{CO}_{2}$ gas

\section{Introduction}

Natural plant fibers such as jute and kenaf are now widely used for automobiles as substitution for glass fibers from viewpoints of sustainability and easy wastability, namely burnability, biodegradability as well as cost. They 
are applied for fabricating interior parts; rear partitions, ceilings, door panels, truck liners, parcel shelves, etc. (see Table 1) (C. Alaves et al., 2010; John Summerscales et al., 2010; Keiichiro Sano and Teruo Kimura, 2010, Kazuya Okubo et al, 2010). They are expected to be used more and more with an increase of automobile production. However, less potential exists to increase those fibers production on the earth since there is less land to cultivate for those natural plants in the tropical regions, for instance South East Asia. Cultivation of new farm lands will let disappear the natural habitat of all kind of creatures. Therefore, we have to find an alternative plant from which similar fibers are extracted. The plant must be abundant and grow naturally without changing lands. What is that? The answer is bamboo. Bamboo is not grass neither wood, while it has two of their characteristics. Bamboo, itself is very strong in its longitudinal direction due to strong fiber bundles penetration its body from the bottom to the top although its monofilaments, other word, pulp is shorter than $\sim 2 \mathrm{~mm}$. If we could extract string-like fiber bundles, they are very useful as substitution of jute and kenaf fibers.

Bamboo fiber bundles (shortly, bamboo fibers) are attracting more and more attention from researchers, and often called 'natural glass fiber' (Kazuya Okubo et al., 2004). In the automotive industry, natural fibers reinforced polymer composites are generally fabricated by press-molding techniques with thermoplastics (mainly polypropylene, polylactic acid may be used), hand lay-up and resin transfer molding techniques with thermosetting plastics (primarily unsaturated polyester) (Ryoko Tokoro et al., 2008; F. P. La Mantia et al., 2011; Jae Kyoo Lim et al., 2005).These techniques reasonably demand flexible fibers, high aspect ratio of fibers and mechanical properties. Compare to other natural fibers, bamboo fibers (precisely fiber bundles) are often brittle due to their thicker diameter as well as chemical composition containing a high content of lignin and hemicelluloses. These compositions play an important role in fiber bundle integration, fiber bundle strength and individual fiber strength. More over, they also affect fiber rigidity, fiber swelling and moisture absorption (G. Bogoeva-Gaceva et al., 2007; Maya Jacob John et al., 2008). For those reasons, one of the purposes of the present study is to find out how to effectively extract thin bamboo fiber bundles from raw bamboo to apply to the automotive inner parts. We conduct different techniques, namely, mechanical extraction, steam explosion and alkaline treatment to extract bamboo fiber bundles. Their mechanical properties are examined.

In comparison with the steam-explosion and mechanical-extraction techniques in Table 2, the alkaline-treatment technique predominantly has some advantages such as cheap equipment, a high respect ratio of fiber, relatively low energy consumption and easy control of fiber property. The control of fiber properties in the automotive industry plays an important role, whose parameters much depend on relationship between bamboo age and processing conditions such as alkali concentration, temperature and immersing time (Ryoko Tokoro et al., 2008; Abhijit P. Deshpande et al., 2000; Keisuke Wakasugi et al., 2010; Hongyan Chen et al., 2009; K. Murali Mohan Rao et al., 2007; Moe Moe Thwe et al., 2003; Nguyen Huy Tung et al., 2004). In addition, this technique is especially suitable to apply to rural areas in Asia where bamboo almost only grows in Forest Mountains with a difficult means of transport from harvest fields to factories of fiber extractions as well as place of product fabrications. However, the alkaline-treatment technique evidently exposes a drawback from wastewater yielding a high $\mathrm{pH}$. This is a big problem when applying them in an industrial scale. Therefore, the second goal of this study is how to control the $\mathrm{pH}$ of wastewater yielding from the alkaline-treatment technique. There are dozens of ways to treat wastewater such as sulfuric acid, hydrochloric acid or nitric acid. However, these materials usually result in a poisonous environment, salt formation in water and are difficult in process control, maintenance of equipment and chemical cost. To avoid these problems, $\mathrm{CO}_{2}$ gas was selected for the neutralization. This technique was able to utilize $\mathrm{CO}_{2}$ emissions from industrial waste and decreasingly contribute to global warming. $\mathrm{CO}_{2}$ gas offered the following advantages over mineral acids due to low toxicity, it required no special protection equipment to handle and could not reduce $\mathrm{pH}$ below 5 even if overdosing occurs. More over, $\mathrm{CO}_{2}$ gas did not form residual anions such as sulfate, chloride as other acids. Its cost was the same as sulfuric acid and about half the price of hydrochloric acid, so it was totally applicable to replace the conventionally used acid (G. Montees-Henandez et al., 2007; R. Pérez-López et al., 2008; Luc Van Ginneken et al., 2004; A. Gangagni Rao et al., 2007; Ankur Gaur et al., 2009).

\section{Materials and Experiments}

\subsection{Raw bamboo}

Raw bamboo was harvested from Moso bamboo of Doshisha University, Kyoto, Japan, and they were extracted by methods as follows:

(1) The mechanical extraction method (Figure 1a)

Raw bamboo (2 8months) was first longitudinal cleaved into small slabs by the roller crusher. The pin-roller looser was used to extract small slabs into coarse fibers before removing fat by the boiler at $90^{\circ} \mathrm{C}$ for 10 hours Then, coarse fibers were put into the dehydrator and finally dried in the Rotary dryer. 
(2) The alkali-treated method (Figure 1b)

Nodes of raw bamboo (2 4 four years old) were first removed and remaining parts were cleaved in longitudinal direction to thin slabs with $20-30 \mathrm{~cm}$ in length and 2-3 $\mathrm{mm}$ in thickness by the slicer. These thin slabs were then immersed in $\mathrm{NaOH}$ solution at $70^{\circ} \mathrm{C}$ for 10 hours. The concentrations of $\mathrm{NaOH}$ were $1 \%, 2 \%, 3 \%$. The $1 \%$ concentration of $\mathrm{NaOH}$ was selected in this study due to the higher mechanical properties of fibers with $1 \%$ than other fibers treated with $2 \%$ and $3 \%$ of $\mathrm{NaOH}$ (see Table (3). The roller looser was used to extract alkali treated slabs into small fibers. Finally, they were washed with fresh water to neutralize, and dried in the oven for 24 hours at $105^{\circ} \mathrm{C}$.

(3) The steam-explosion method (Figure 1c)

Raw bamboo (2 4 four years old) was first cut into bamboo culms with $70-80 \mathrm{~cm}$ in length by saw machine, and put into an autoclave with over-heated steam at $175^{\circ} \mathrm{C}$ and $0.7-0.8 \mathrm{MPa}$ for 60 minutes. Then, the steam was suddenly released for 5 minutes and the cycles of sudden-steam release were continuously repeated for 9 times to assure the complete facture of cell walls. Finally, they were washed in hot water with addition of soap at $90-95^{\circ} \mathrm{C}$ for 15 minutes to remove ash and dried in the oven for 24 hours at $105^{\circ} \mathrm{C}$.

\subsection{Scanning electron microscopy observations}

Microstructures of bamboo fiber were examined by scanning electron microscopy (SEM) using JSM-7001FD equipment. With the cross-sectional area at the imaging surface, the bamboo fiber was put in to a plastic mould with shape of cylinder of $3 \mathrm{~mm}$ in thickness as shown in Fig. 2. Epoxy resin was used as matrix to hold bamboo fiber during the testing process. Epoxy resin was first poured into the mould in which the bamboo fiber was placed, and the mould was then put into heat-oven at $120^{\circ} \mathrm{C}$ for 4 hours. The fabricated specimens of SEM were polished by the Ecomet 3000 polisher until the specimen surfaces were clear and smooth, and finally cut into the appropriate shape for taking SEM by a slow-speed diamond cutter. Prior to SEM observation, all specimens including cross-section and longitudinal-section were coated with a thin layer of gold to avoid electrical charging.

\subsection{Tensile test}

Average diameters of bamboo fiber bundle were measured by microscope (the number of observations was about 50). Before the tensile test, bamboo fiber bundle was glued on a sheet of paper with length of $50 \mathrm{~mm}$, thickness of $0.5-1 \mathrm{~mm}$ and gauge length of $25.4 \mathrm{~mm}$ as in Figure 3. Then the gauge positions of paper were cut after chucking it on testing machine to apply tensile load. The tensile test was measured under $1 \mathrm{~mm} / \mathrm{min}$ of cross-head speed.

\subsection{Chemical composition}

Untreated, alkaline treated and steam exploded fiber bundles were chemically analyzed for hemicelluloses, cellulose, lignin contents by using TAPPI standard T222om- 83 and T250um-85.

\subsection{Moisture content}

Moisture contents of bamboo fiber bundles were tested by Humidity Cabinet LHL-112 equipment using ASTM D2495-07 standard. Moisture content (M\%) was calculated from equation following as:

$$
\mathrm{M} \%=\frac{\mathrm{Wt}_{\mathrm{t}}-\mathrm{W}_{\mathrm{o}}}{\mathrm{W}_{\mathrm{o}}} \times 100
$$

Wt: weight of the specimen at the time $t$

Wo: weight of the initial specimen after drying

\subsection{Interfacial shear strength}

To evaluate interfacial behavior of unsaturated polyester and polypropylene resin with bamboo fiber bundle, pull-out test performed under $1 \mathrm{~mm} / \mathrm{min}$ of cross-head speed with specimens as shown in Figure 4. Interfacial shear strength was calculated by the following equation.

$$
\text { Tinterface }=\frac{\mathrm{P}}{\pi \mathrm{dl}}
$$

P: pull-out load, N

$\mathrm{d}$ : diameter of bamboo fiber bundle, $\mathrm{mm}$ 
1: length of embedded bamboo fiber bundle into resin, $\mathrm{mm}$

\subsection{Physic chemical characteristics of wastewater and neutralization apparatus}

Wastewater in this study was collected from the alkaline-treatment process. The basic quality parameters such as $\mathrm{pH}$, total dissolved solids (TDS), total solid (TS), total suspended solids (TSS), volatile suspended solids (VSS), volatile dissolved solids (VDS) were analyzed according to APHA standard (P.R Sreemahadevan Pillai, 2010). Table 4 resulted in the characteristics of wastewater.

The used apparatus in neutralization were described as shown in Figure 5. Alkaline wastewater was first put into a chamber with volume of $1000 \mathrm{ml}$, and then $\mathrm{CO}_{2}$ gas was dispersed by a stirring system. Temperature of the chamber was controlled by an automatic heat system. $\mathrm{pH}$ value was continuously determined at a series time interval of 10 minutes until $\mathrm{pH}$ reached 7.0.

\section{Results and Discussion}

\subsection{Microstructure configurations, chemical compositions and mechanical properties of bamboo fiber}

Observations of SEM pictures in Figure 1a-c showed single fibers in the extracting methods were longitudinally aligned, and they were together bonded by lignin and hemicelluloses with the different bonding levels. In the case of untreated and alkaline treated fibers, the single-fiber bonding was strong by rich lignin areas. In contrast, the single-fiber bonding of steam exploded fibers relatively weakened. Most lignin content was extracted outside the fiber bundle, and significantly condensed on fiber surfaces under the repeating cycles of high temperature and pressure (see 2.1). Figure 1c also showed the formation of holes and round cracks inside fiber bundles (Maha M. Ibrahim et al., 2011). Determination of chemical compositions and mechanical properties of bamboo fibers as in Table 5 evidently exhibited relationship between chemical compositions (lignin and hemicelluloses content) and mechanical properties. The removal of lignin and hemicelluloses in fiber structure led to a decrease in their mechanical properties as well as in diameters. Table 5 also indicated that fiber bundles more softened with the alkaline-treatment and steam-explosion technique. Their Young's modulus values were respectively $26.1 \pm 14.5$ and $25.7 \pm 14.0 \mathrm{GPa}$, and lower than the untreated fibers of $38.2 \pm 16.0 \mathrm{GPa}$. These results were completely suitable to those of previous researchers, which asserted lignin and hemicelluloses playing a role as a matrix in natural fibers (G. Bogoeva-Gaceva et al., 2007; Maya Jacob John et al., 2008; Nguyen Huy Tung et al., 2004).

\subsection{Moisture absorption}

In fabrication of green-composite materials, moisture content plays an important role, which directly affects manufacturing process, product properties as well as their quality (G. Bogoeva-Gaceva et al., 2007; A. Athijayamani et al., 2009; F. Gouanvé et al., 2007). To investigate the characteristics of moisture absorptions in this study, bamboo fibers were determined at $20^{\circ} \mathrm{C}$ and $50 \%, 60 \%, 70 \%, 80 \%$ and $90 \%$ relative humidity. Bamboo fibers were weighted at a series of time intervals until moisture absorption reached its equilibrium level, and the value of moisture content increased in the square root of time (see Figure 6a-e). This completely corresponded to behavior of natural fibers as well as green-composite materials (A. Athijayamani et al., 2009; F. Gouanvé et al., 2007). In Figure 6a-e, the result showed that when bamboo fibers were put into a chamber with different relative humidity levels, their moisture contents together increased in elevation of relative humidity level. The curve of equilibrium was formed from moisture content and relative humidity with difference of fiber types as shown in Figure 6f. The result also presented that extracted fibers from the steam-explosion and alkaline-treatment technique offered lower moisture contents than untreated fibers at all relative humidity levels, and the difference of moisture content between steam exploded and alkaline treated fibers was not considerably. The result also revealed the relationship between lignin, hemicelluloses and moisture content (see Table 5 and Figure 6f).

\subsection{Interfacial shear strength}

Figure 7a-b shows the investigated relation between bamboo fibers and resin for interfacial shear strength (IFSS). The results revealed that the IFSS of alkaline treated fibers was higher than that of steam exploded and untreated fibers with unsaturated polyester and polypropylene. Observation of SEM imagine in Figure $1 \mathrm{~b}$ indicated that the surface of treated fibers was smooth and clear and its interfacial bonding with respect to polypropylene and unsaturated polyester strengthened. In the case of untreated fibers in Figure 1a, its surface obtained a lot of hemicelluloses, lignin, soft cell, and some impureness which led to incompatibility between untreated fibers and resins. Hence, the interfacial bonding weakened. With steam exploded fibers under effect on high temperature and pressure, its surface was covered a considerable amount of lignin as shown in Figure 1c. That led to a decrease of the adhesion between steam explosion fibers and resins. 


\subsection{Effect of flow rate on $\mathrm{pH}$ of wastewater}

Wastewater yielding from the alkaline-treatment technique is often a drawback to apply alkali treated fibers on an industrial scale. In the present study, $\mathrm{CO}_{2}$ gas was particularly selected to control $\mathrm{pH}$ of wastewater. In Table 4 , wastewater had a high $\mathrm{pH}$ 10.8. This was a difficult problem to discharge it from manufactory to lakes, rivers and namely public water. In order to overcome this problem, $\mathrm{CO}_{2}$ gas was used as a neutralization agent. Its reactions with sodium hydroxide included steps from (1) to (5) as below:

$\begin{array}{lllllll}\mathrm{CO}_{2}(\mathrm{~g}) & + & \mathrm{H}_{2} \mathrm{O} & \leftrightarrow & \mathrm{CO}_{2}(\mathrm{aq}) & + & \mathrm{H}_{2} \mathrm{O} \\ \mathrm{CO}_{2}(\mathrm{aq}) & + & \mathrm{H}_{2} \mathrm{O} & \leftrightarrow & \mathrm{H}_{2} \mathrm{CO}_{3} & & \\ \mathrm{H}_{2} \mathrm{CO}_{3} & + & \mathrm{OH}^{-}(\mathrm{aq}) & \rightarrow & \mathrm{HCO}_{3}^{-}(\mathrm{aq}) & + & \mathrm{H}_{2} \mathrm{O} \\ \mathrm{HCO}_{3}{ }^{-}(\mathrm{aq}) & + & \mathrm{OH}^{-} & \rightarrow & \mathrm{CO}_{3}{ }^{2-}(\mathrm{aq}) & + & \mathrm{H}_{2} \mathrm{O} \\ \mathrm{CO}_{3}{ }^{2-}(\mathrm{aq}) & + & 2 \mathrm{Na}^{+} & \rightarrow & \mathrm{Na}_{2} \mathrm{CO}_{3} & & \end{array}$

$\mathrm{CO}_{2}$ gas was initially dissolved in solution and reacted with water to form $\mathrm{H}_{2} \mathrm{CO}_{3}$. Once equilibrium was established between $\mathrm{CO}_{2}$ gas and $\mathrm{H}_{2} \mathrm{CO}_{3}, \mathrm{H}_{2} \mathrm{CO}_{3}$ further dissociate into $\mathrm{HCO}_{3}^{-}$and $\mathrm{CO}_{3}{ }^{-}$ions. The buffer solution acted a mean of keeping $\mathrm{pH}$ at a nearly constant value due to existence $\mathrm{HCO}_{3}{ }^{-} \cdot \mathrm{CO}_{3}{ }^{2-}$ ions were the dominant species occurring in solution and these ions reacted with $\mathrm{Na}^{+}$ions to form $\mathrm{Na}_{2} \mathrm{CO}_{3}$. Figure 8 showed that $\mathrm{CO}_{2}$ gas was put into a chamber with the stirring speed of $400 \mathrm{rpm}$ and flow rate of $5 \mathrm{ml} / \mathrm{minutes}$ at room temperature. At that time, $\mathrm{pH}$ of wastewater decreased from $\mathrm{pH} 10.8$ to $\mathrm{pH} 7.0$ for 130 minutes. Then $\mathrm{CO}_{2}$ gas was continuously put into the chamber, and $\mathrm{pH}$ did not much decrease from $\mathrm{pH} 7.0$ to $\mathrm{pH} 6.48$ for 130 minutes. This could be due to the wastewater that was completely saturated by $\mathrm{CO}_{2}$ gas. Figure 8 also shows the comparison with various flow rates of 3,7 and $9 \mathrm{ml} /$ minutes for 260,125 and 110 minutes. They all reached $\mathrm{pH}$ 7.0. In the case of the flow rate of $3 \mathrm{ml} /$ minutes, $\mathrm{pH}$ slowly decreased in a long time. In the other hand, with the flow rate of 7 and $9 \mathrm{ml} /$ minutes, the reaction of $\mathrm{CO}_{2}$ gas with wastewater quickly happened for a short time, and consumptions of $\mathrm{CO}_{2}$ gas approximately were $910 \mathrm{ml}$ and $990 \mathrm{ml}$, respectively. With a flow rate of $5 \mathrm{ml} / \mathrm{minutes}$, consumption of $\mathrm{CO}_{2}$ gas was $650 \mathrm{ml}$.

\subsection{Effect of stirring speed and temperature on $\mathrm{pH}$}

Stirring speed was one of the important parameters, which directly affected the $\mathrm{pH}$ value of wastewater. With a suitable stirring speed, $\mathrm{CO}_{2}$ gas was quickly dispersed into wastewater with an optimal content.

Figure 9a indicated that with a stirring speed of $500 \mathrm{rpm}$ the reaction time to obtain a $\mathrm{pH}$ of 7.0 was 110 minutes. This value was better when compared with the 300 and $400 \mathrm{rpm}$ stirring speeds. This was due to increase of dissolution of $\mathrm{CO}_{2}$ gas in wastewater when the stirring speed changed. However, observation of stirring speeds of 500 and $600 \mathrm{rpm}$ showed that these curves nearly overlapped, and that their values of $\mathrm{pH}$ reached saturation after 220 minutes. Figure $9 \mathrm{~b}$ also presented that there was no effect of temperature on $\mathrm{pH}$ of wastewater, and most of the curves nearly overlapped at room temperature, 30,50 and $70^{\circ} \mathrm{C}$.

\section{Conclusions}

In this study, the steam-explosion, mechanical-extraction and alkaline-treatment technique were applied to extract bamboo fiber bundles from raw bamboo with different age, and the effect of $\mathrm{CO}_{2}$ gas on the $\mathrm{pH}$ value of alkaline wastewater was also determined.

Some conclusions obtained from this study are:

1. Microstructures of bamboo fiber were determined by using scanning electron microscope. The results showed the single fibers were longitudinally aligned in the flat-wise direction. They were together bonded by hemicelluloses and lignin with different bonding levels.

2. Mechanical properties of fiber bundle and their interfacial shear strength (IFSS) with typical resins such as unsaturated polyester and polypropylene are related to lignin and hemicelluloses content in chemical composition. The experimental results also proved that the IFSS of alkaline treated fibers were better than that of steam exploded and untreated fibers.

3. Moisture absorptions of bamboo fibers at $50,60,70,80$ and $90 \%$ relative humidity at $20^{\circ} \mathrm{C}$ was also determined. The results showed that the difference of moisture content of the alkaline treated and the steam exploded fibers was much lower than that of the untreated fibers at all relative humidity levels.

4. Wastewater of the alkaline-treatment technique was treated by $\mathrm{CO}_{2}$ gas, and the ratio of wastewater to $\mathrm{CO}_{2}$ gas was $1000 \mathrm{ml}$ to $650 \mathrm{ml}$. pH of wastewater was decreased from 10.8 to 7 within 110 minutes. 


\section{References}

A. Athijayamani, M. Thiruchitrambalam, U. Natarajan, \& B. Pazhanivel. (2009). Effect of moisture absorption on the mechanical properties of randomly oriented natural fibers/polyester hybrid composite. Materials Science and Engineering A, 517, 344-353. http://dx.doi.org/10.1016/j.msea.2009.04.027

A. Gangagni Rao, T. Sasi Kanth Reddy, S. Surya Prakash, J. Vanajakshi, Johny Joseph, \& P. N. Sarma. (2007). $\mathrm{pH}$ regulation of alkaline wastewater with carbon dioxide: A case study of treatment of brewery wastewater in UASB reactor coupled with absorber. Bioresource Technology, 98, 2131-2136. http://dx.doi.org/10.1016/j.biortech.2006.08.011

Abhijit P. Deshpande, M. BhaskarRao, \& C. Lakshmana Rao. (2000). Extraction of bamboo fibers and their use as reinforcement in polymeric composites. Journal of Applied Polymer Science, 76, 83-92. http://dx.doi.org/10.1002/(SICI)1097-4628(20000404)76:1<83::AID-APP11>3.0.CO;2-L.

Ankur Gaur, Jin-Won Park, Jung-Hwa Jang, Sanjeev Maken, JooJae Lee, \& Ho-Jun Song. (2009). Characteristics of alkaline wastewater neutralization for $\mathrm{CO}_{2}$ capture landfill gas(LFG). Energy Fuels, 23, 5467-5473. http://dx.doi.org/10.1021/ef900615h

C. Alves, P. M. C. Ferrão, A. J. Silva, L. G. Reis, M. Freitas, L. B. Rodrigues, \& D. E. Alves. (2010). Ecodesign of automotive components making use of natural jute fiber composites. Journal of Cleaner Production, 18, 313-327. http://dx.doi.org/ 10.1016/j.jclepro.2009.10.022

F. Gouanvé, S. Marais, A. Bessadok, D. Langevin, \& M. Métayer. (2007). Kinetics of water sorption in flax and PET fibers. European Polymer Journal, 43, 586-598. http://dx.doi.org/ 10.1016/j.eurpolymj.2006.10.023

F. P. La Mantia, \& M. Morreale. (2011). Green composites: A brief review. Composites: Part A: applied science and manufacturing, 42, 579-588. http://dx.doi.org/10.1016/j.compositesa.2011.01.017

G. Bogoeva-Gaceva, M. Avella, M. Malinconico, A. Buzarovska, A. Grozdanov, G. Gentile., \& M. E. Errico. (2007). Natural fiber eco-composites. Polymer Composites, 98-107. http://dx.doi.org/10.1002/pc.20270

G. Montees-Hernandez, F. Renard, N. Geoffroy, L. Charlet, \& J. Pironon. (2007). Calcite precipitation from $\mathrm{CO}_{2}-\mathrm{H}_{2} \mathrm{O}-\mathrm{Ca}(\mathrm{OH})_{2}$ slurry under high pressure of $\mathrm{CO}_{2}$. Journal of Crystal Growth, 308, 228-236. http://dx.doi.org/10.1016/j.jcrysgro.2007.08.005

Hongyan Chen, Menghe Miao, \& Xin Ding. (2009). Influence of moisture absorption on the interfacial strength of bamboo/vinyl ester composites. Composite: Part A, 40, 2013-2019. http://dx.doi.org/10.1016/j.compositesa.2009.09.003

Jae Kyoo Lim, Jun Yong Choi, \& Hyo Jin Kim. (2005). Effects of matrix on mechanical property test bamboo fiber composite material. Key engineering Materials, 297-300, 1529-1533. http://dx.doi.org/10.4028/www.scientific.net/KEM.297-300.1529

Jonh Summerscales, Nilmini Dissanayake, Amandeep Virk, \& Waynehall. (2010). A review of bast fibres and their composites. Composite: Part A, 41, 1336-1344. http://dx.doi.org/10.1016/j.compositesa.2010.05.020

K. Murali Mohan Rao, \& K. Mohana Rao. (2007). Extraction and tensile properties of natural fibers: Vakka, date and bamboo. Composite Structures, 77, 288-295. http://dx.doi.org/10.1016/j.compstruct.2005.07.023

Kazuya Okubo, Toru Fujii, \& Xiaochen Fu. (2010). An application of bamboo fibers in Japan. Effect of needle punching and spring-back molding on stiffness of stampable bamboo fiber sheet processed with pressed mat. VCCS-5, November, Hanoi, Vietnam

Kazuya Okubo, Toru Fujii, \& Yuzo Yamamoto. (2004). Development of bamboo-based polymer composites and their mechanical properties. Composite: Part A, 35, 377-383. http://dx.doi.org/10.1016/j.compositesa.2003.09.017

Keiichiro Sano, \& Teruo Kimura. (2010). Trend of natural fiber reinforced plastic for automobile industry in Germany and Japan. Proceeding of The Sixth international Workshop on Green Composites (IWGC-6)-109-112

Keisuke Wakasugi, Kazuya Okubo, \& Toru Fujii. (2010). Improvement of strength of bamboo fiber paper by addition of MFC (Micro Fibrillated Cellulose). Proceeding of The Sixth International Workshop on Green Composites (IWGC-6), 178-181.

Luc Van Ginneken, Veronika Dutré, Walter Adriansens, \& Herman Weyten. (2004). Effect of liquid and supercritical carbon dioxide treatments on the leaching performance of a cement-stabilised waste form. Journal of Supercritical Fluid, 30, 175-188. http://dx.doi.org/10.1016/j.supflu.2003.07.004 
Maha M. Ibrahim, Waleed K. El-Zawawy, Yasser R. Abdel-Fattah, Nadia A. Soliman, \& Foster A. Agblevor. (2011). Comparison of alkaline pulping with steam explosion for glucose production from rice straw, Carbohydrate Polymers, 83, 720-726. http://dx.doi.org/10.1016/j.carbpol.2010.08.046

Maya Jacob John, \& Rajesh D. Anandjiwala. (2008). Recent developments in chemical modification and characterization of natural fiber-reinforced composites. Polymer composites, 187-207. doi: 10.1002/pc.20461, http://dx.doi.org/10.1002/pc.20461

Moe Moe Thwe, \& Kin Liao. (2003). Durability of bamboo-glass fiber reinforced polymer matrix hybrid composites. Composite Science and Technology, 63, 375-387. http://dx.doi.org/10.1016/S0266-3538(02)00225-7

Nguyen Huy Tung, Hiroshi Yamamoto, Takashi Matsuoka, \& Toru Fujii. (2004). Effect of surface treatment on interfacial strength bamboo fiber and PP resin. JSME International Journal Series A, 47, 561-565. http://dx.doi.org/10.1299/jsmea

P. R Sreemahadevan Pillai. (2010). New age international publishers, A comprehensive laboratory manual for environmental science and engineering.

R. Pérez-López, G.Montes-Hernandez, J.M. Nieto, F. Renard, \& L.Charlet. (2008). Carbonation of alkaline paper mill waste to reduce $\mathrm{CO}_{2}$ greenhouse gas emssision into the atmosphere. Applied Geochemistry, 23, 2292-2300. http://dx.doi.org/10.1016/S0048-9697(99)00025-X

RyokoTokoro, Duc Minh Vu, Kazuaya Okubo, Tatsuya Takanaka, Toru Fujii, \& Takayasu Fujiura. (2008). How to improve mechanical properties of polylactic acid with bamboo fibers. Journal of Material Science, 43, 775-787. http://dx.doi.org/10.1007/s10853-007-1994-y

Table 1. Automakers using green-composites (Keiichiro Sano \& Teruo Kimura, 2010)

\begin{tabular}{|l|c|c|l|}
\hline Manufacturer & Fiber & Resin & \multicolumn{1}{|c|}{ Parts } \\
\hline Toyota & $\begin{array}{c}\text { Kenaf, sisal, } \\
\text { ramie }\end{array}$ & $\begin{array}{c}\text { Polypropylene, polylactic } \\
\text { acid }\end{array}$ & $\begin{array}{l}\text { Door trim, inner board, roof lining, cover } \\
\text { board of the spare tire }\end{array}$ \\
\hline Mercedes & Flax, hemp & Polypropylene & $\begin{array}{l}\text { Inner board of instrumental panel, door, } \\
\text { pillar inners, head liner and trunk } \\
\text { components. }\end{array}$ \\
\hline Mitsubishi & Bamboo & Polybutylene succinate & Inner board of trunk door panel. \\
\hline BMW & Flax & polypropylene & Inner board of door panel. \\
\hline
\end{tabular}


Table 2. Comparison of different extraction methods of bamboo fibers

\begin{tabular}{|c|c|c|c|c|c|c|c|}
\hline Method & $\begin{array}{c}\text { Cost of } \\
\text { equipment }\end{array}$ & $\begin{array}{c}\text { Energy } \\
\text { consumption }\end{array}$ & $\begin{array}{l}\text { Installing } \\
\text { area }\end{array}$ & $\begin{array}{c}\text { Environmental } \\
\text { impact }\end{array}$ & $\begin{array}{c}\text { Aspect ratio } \\
\text { of fiber }\end{array}$ & $\begin{array}{l}\text { Control of } \\
\text { fiber } \\
\text { property }\end{array}$ & $\begin{array}{c}\text { Bamboo age and } \\
\text { species }\end{array}$ \\
\hline $\begin{array}{l}\text { Mechanical } \\
\text { extraction }\end{array}$ & $\begin{array}{c}\text { Reasonably } \\
\text { expensive }\end{array}$ & $\begin{array}{c}\text { Relatively } \\
\text { low }\end{array}$ & Small & No & Low & Acceptable & $\begin{array}{c}\text { Young } \\
(2 \sim 8 \text { months })\end{array}$ \\
\hline $\begin{array}{l}\text { Alkali } \\
\text { treatment }\end{array}$ & \begin{tabular}{|c|} 
Cheap as \\
long as \\
excluding \\
waste water \\
treatment
\end{tabular} & Medium & Huge & Yes & High & Good & $\begin{array}{c}\text { Thin F.: } \\
\sim 12 \text { months } \\
\text { Medium F.: } 1 \sim 2 \\
\text { years. } \\
\text { Coarse F.: } \\
\text { 3years. } \sim\end{array}$ \\
\hline $\begin{array}{l}\text { Steam } \\
\text { explosion }\end{array}$ & Expensive & High & Large & No & High & Good & $\begin{array}{c}\text { Preferable: } \\
\text { younger than } 2 \\
\text { years. } \\
\text { Thick F.: } \sim 5 \\
\text { years. }\end{array}$ \\
\hline
\end{tabular}

Table 3. Mechanical properties of bamboo fiber bundle with respect to $\mathrm{NaOH}$ concentration

\begin{tabular}{|l|c|c|c|c|}
\hline & $\begin{array}{c}\text { Fiber diameter, } \\
(\mu \mathrm{m})\end{array}$ & $\begin{array}{c}\text { Tensile strength, } \\
(\mathrm{MPa})\end{array}$ & $\begin{array}{c}\text { Young`s modulus, } \\
(\mathrm{GPa})\end{array}$ & $\begin{array}{c}\text { Maximum strain at } \\
\text { failure, }(\%)\end{array}$ \\
\hline $\mathrm{NaOH} 1 \%$ & $230 \pm 180$ & $395 \pm 155$ & $26.1 \pm 145$ & $2.82 \pm 1.3$ \\
\hline $\mathrm{NaOH} \%$ & $218 \pm 175$ & $360 \pm 170$ & $25.2 \pm 13.3$ & $2.62 \pm 1.2$ \\
\hline $\mathrm{NaOH} \%$ & $209 \pm 180$ & $324 \pm 170$ & $23.7 \pm 12.5$ & $2.54 \pm 1.2$ \\
\hline
\end{tabular}

Table 4. Characteristics of wastewater

\begin{tabular}{|l|c|c|c|c|c|c|}
\hline Parameters & PH & TS, mg/l & TSS, mg/l & TDS, mg/l & VSS, mg/l & VDS, mg/l \\
\hline Value & 10.8 & 44.040 & 41.380 & 2660 & 840 & 22.140 \\
\hline
\end{tabular}

Table 5. Chemical compositions and mechanical properties of bamboo fiber bundle

\begin{tabular}{|l|c|c|c|c|c|c|c|}
\hline & $\begin{array}{c}\text { Fiber } \\
\text { diameter, } \\
(\mu \mathrm{m})\end{array}$ & $\begin{array}{c}\text { Tensile } \\
\text { strength, } \\
(\mathrm{MPa})\end{array}$ & $\begin{array}{c}\text { Young's } \\
\text { modulus, } \\
(\mathrm{GPa})\end{array}$ & $\begin{array}{c}\text { Maximum } \\
\text { strain at } \\
\text { failure, } \\
(\%)\end{array}$ & $\begin{array}{c}\text { Lignin, } \\
(\%)\end{array}$ & $\begin{array}{c}\text { Hemi } \\
\text { celluloses, } \\
(\%)\end{array}$ & $\begin{array}{c}\text { Cellulose, } \\
(\%)\end{array}$ \\
\hline Untreated & $262 \pm 160$ & $420 \pm 170$ & $38.2 \pm 16.0$ & $9.8 \pm 2.5$ & 24.4 & 25.2 & 48.5 \\
\hline Alkaline treated & $230 \pm 180$ & $395 \pm 155$ & $26.1 \pm 14.5$ & $2.82 \pm 1.3$ & 22.6 & 16.4 & 48.8 \\
\hline Steam exploded & $195 \pm 150$ & $308 \pm 185$ & $25.7 \pm 14.0$ & $2.51 \pm 1.2$ & 23.3 & 7.4 & 47.4 \\
\hline
\end{tabular}




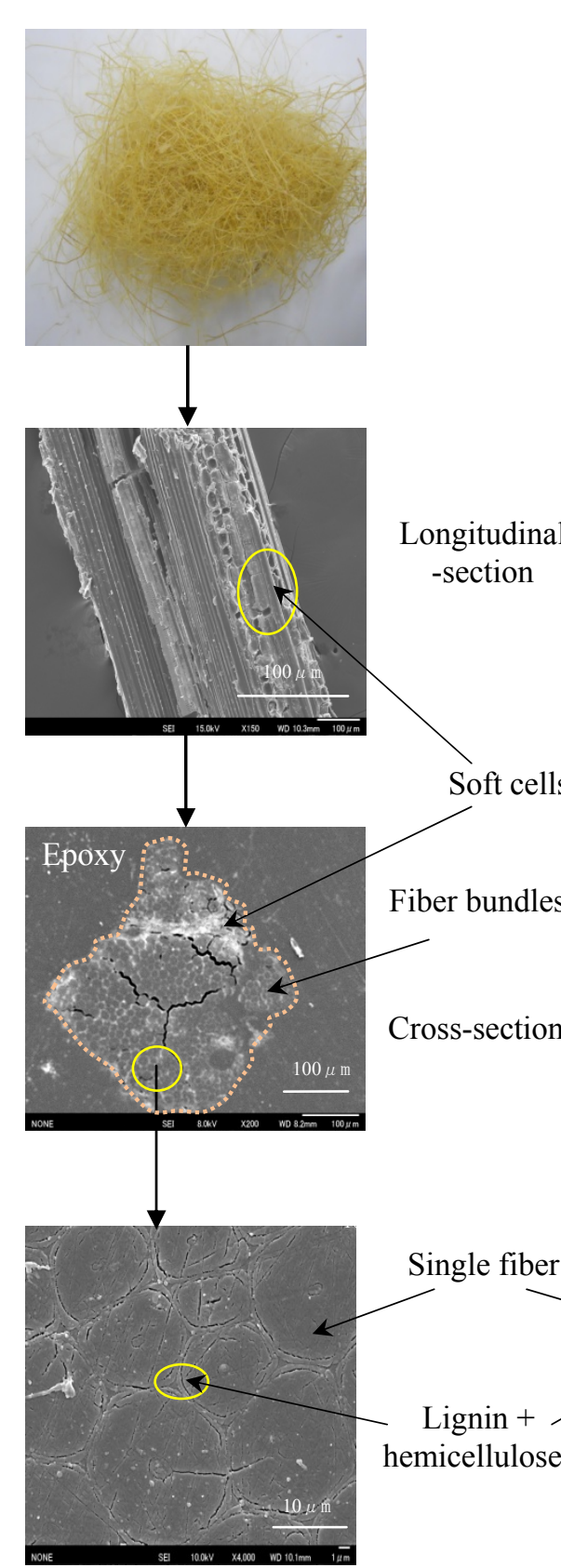

(a)
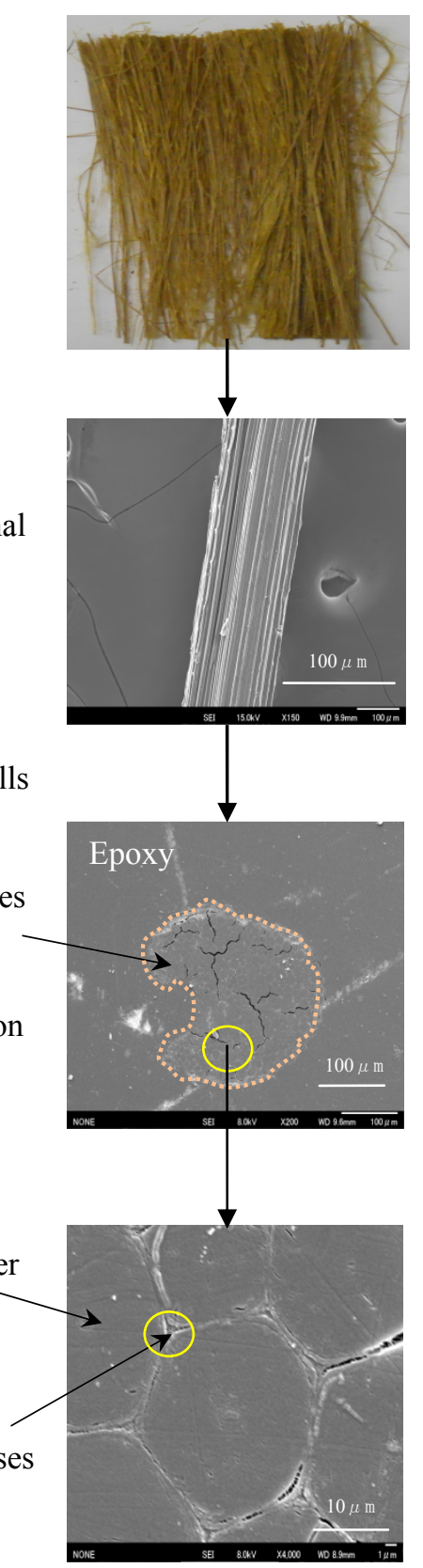

( b )

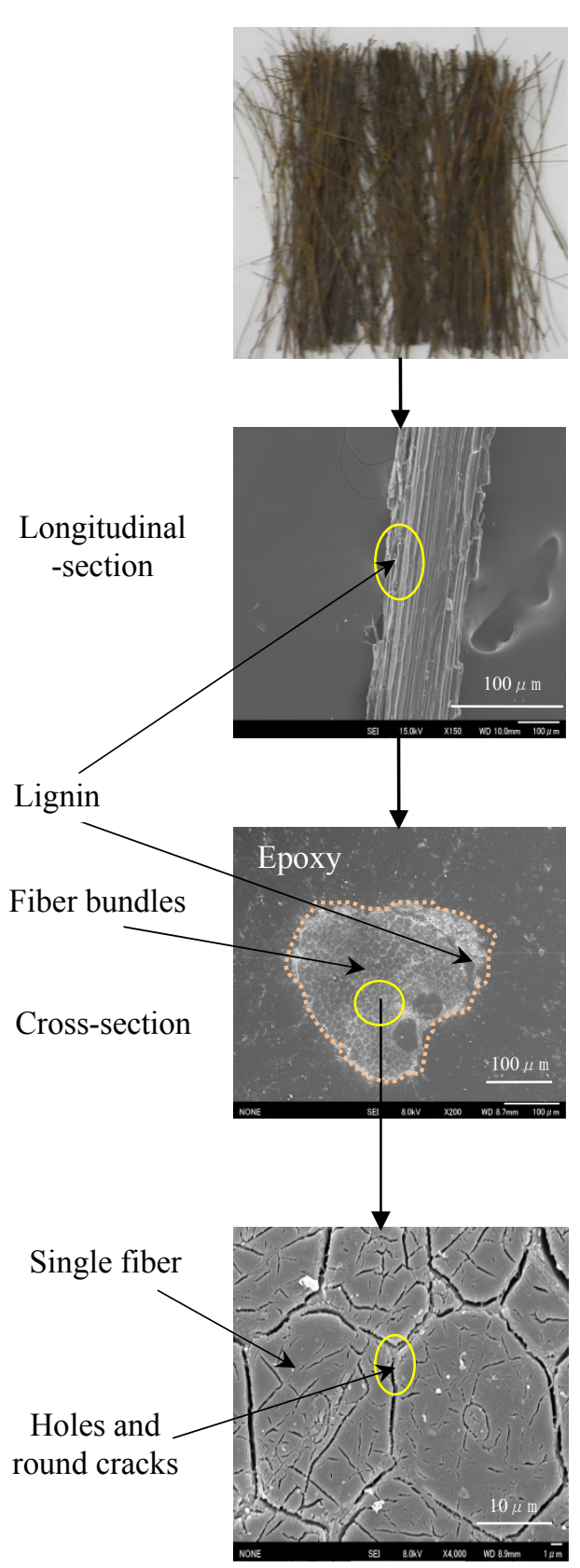

(c)

Figure 1. SEM imagines for side-view and cross-section surfaces of bamboo fiber

(a) Untreated fiber, (b) Alkaline treated fiber, (c) Steam exploded fiber 


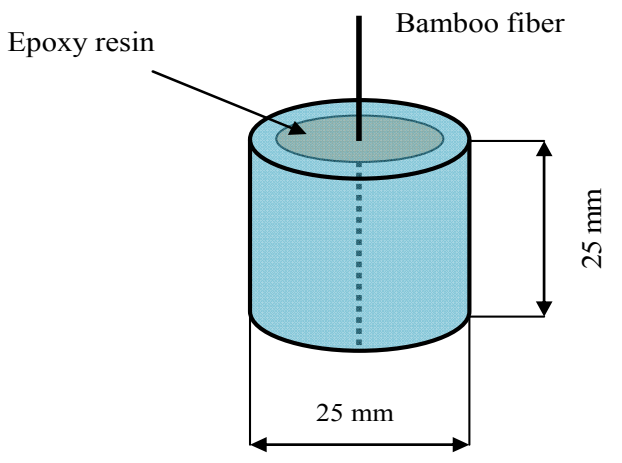

Figure 2. Preparation of cross-section surface

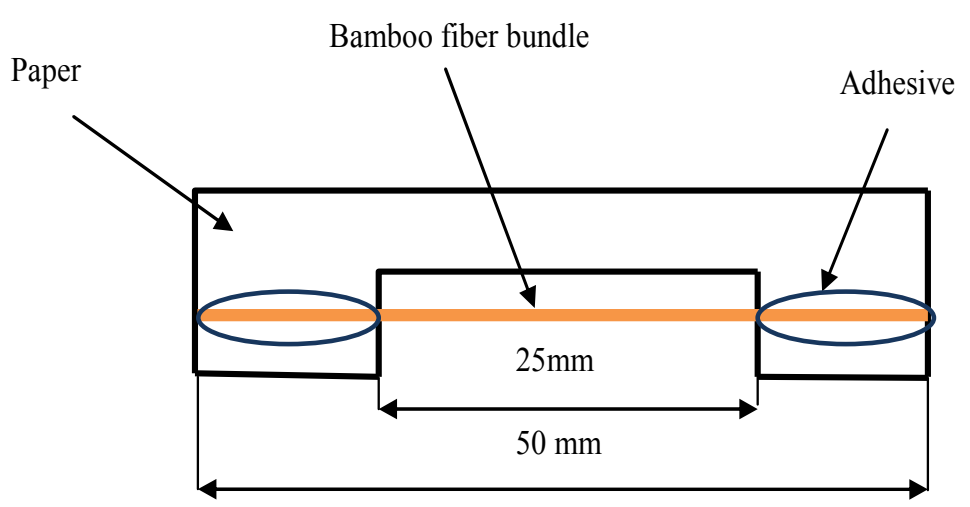

Figure 3. Tensile test method

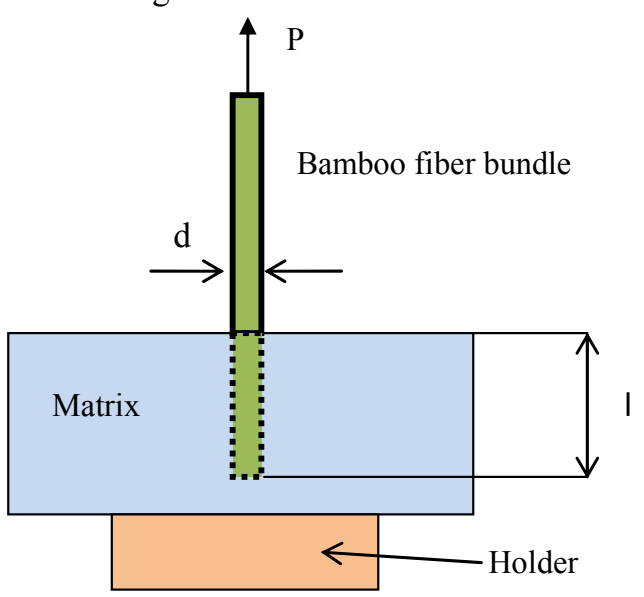

Figure 4. Pull-out test method of bamboo fiber bundle

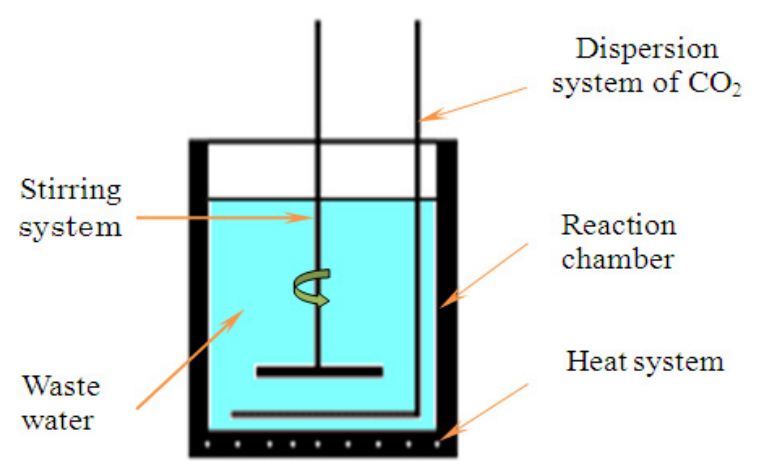

Figure 5. Reaction apparatus of $\mathrm{CO}_{2}$ gas with alkaline wastewater 

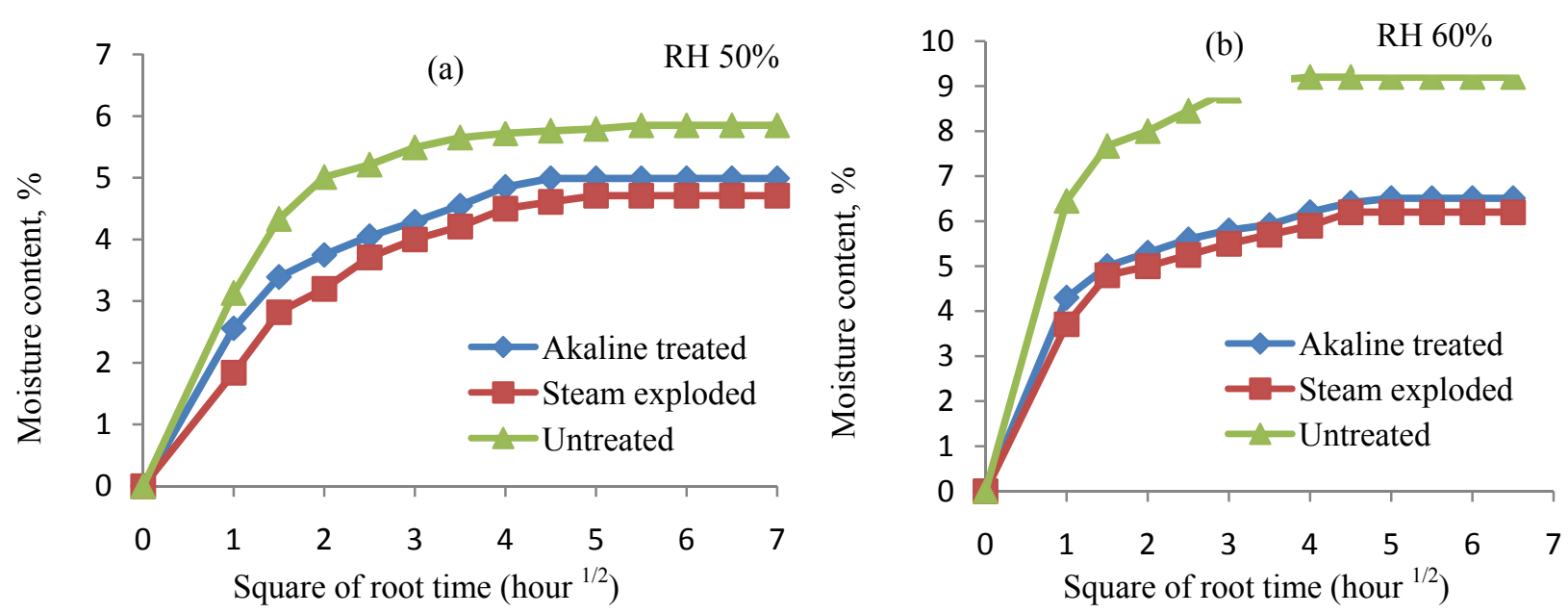

(c)

RH $70 \%$
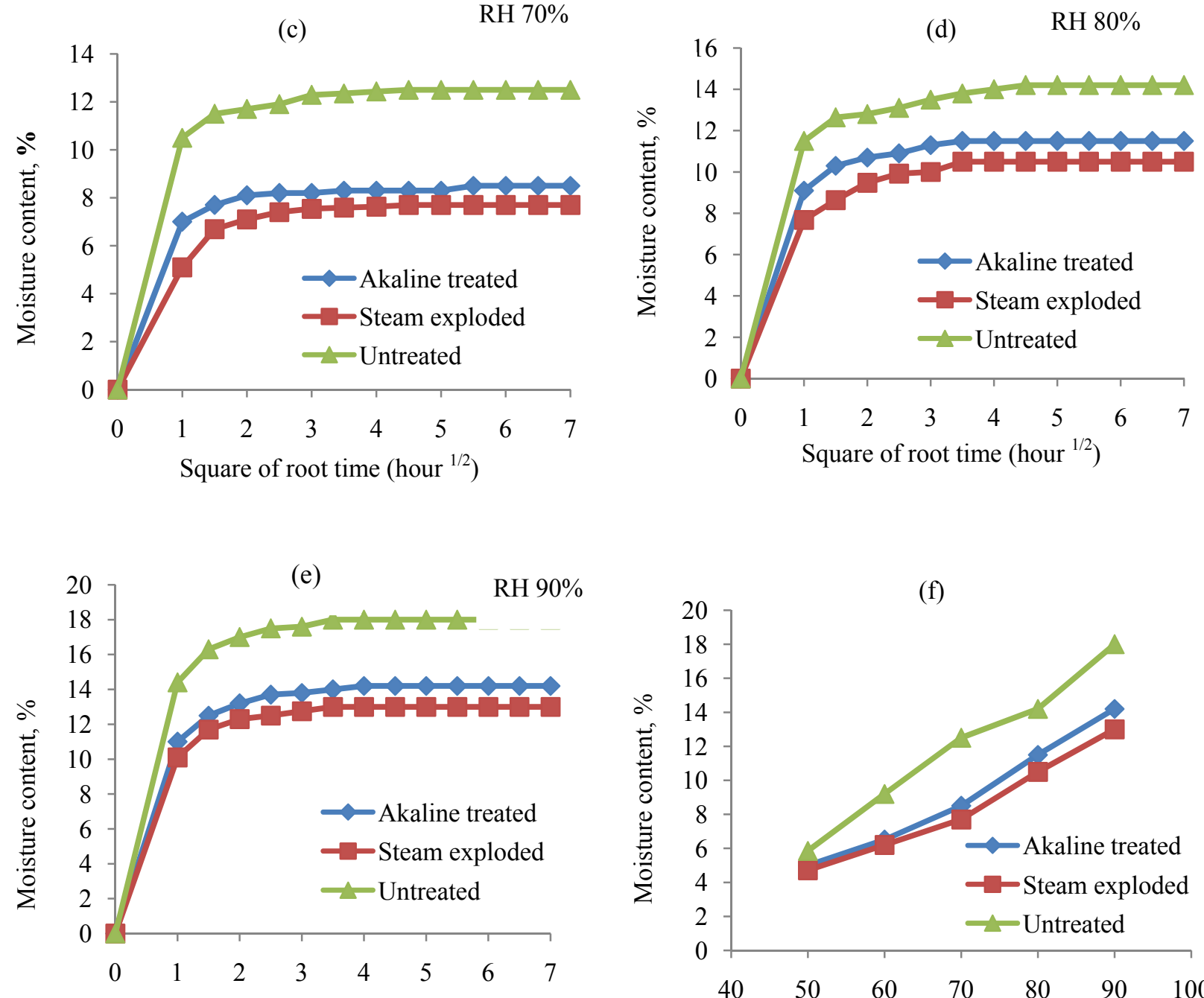

Square of root time (hour ${ }^{1 / 2}$ )

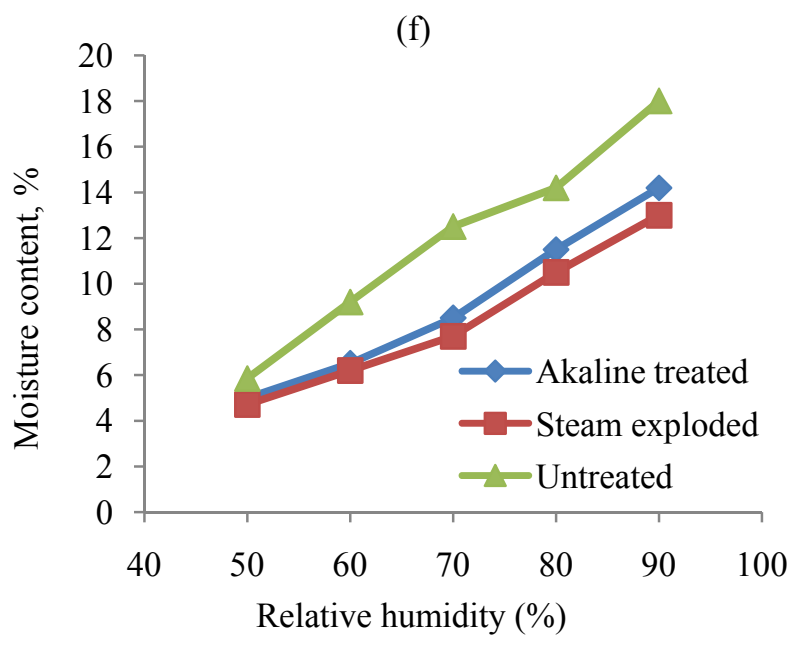

Figure 6. Moisture content curves of bamboo fiber at different relative humidity: 50\%(a), 60\%(b), 70\%(c), 80\%(d), $90 \%(e)$ and relationship between equilibrium moisture content and relative humidity(f) 

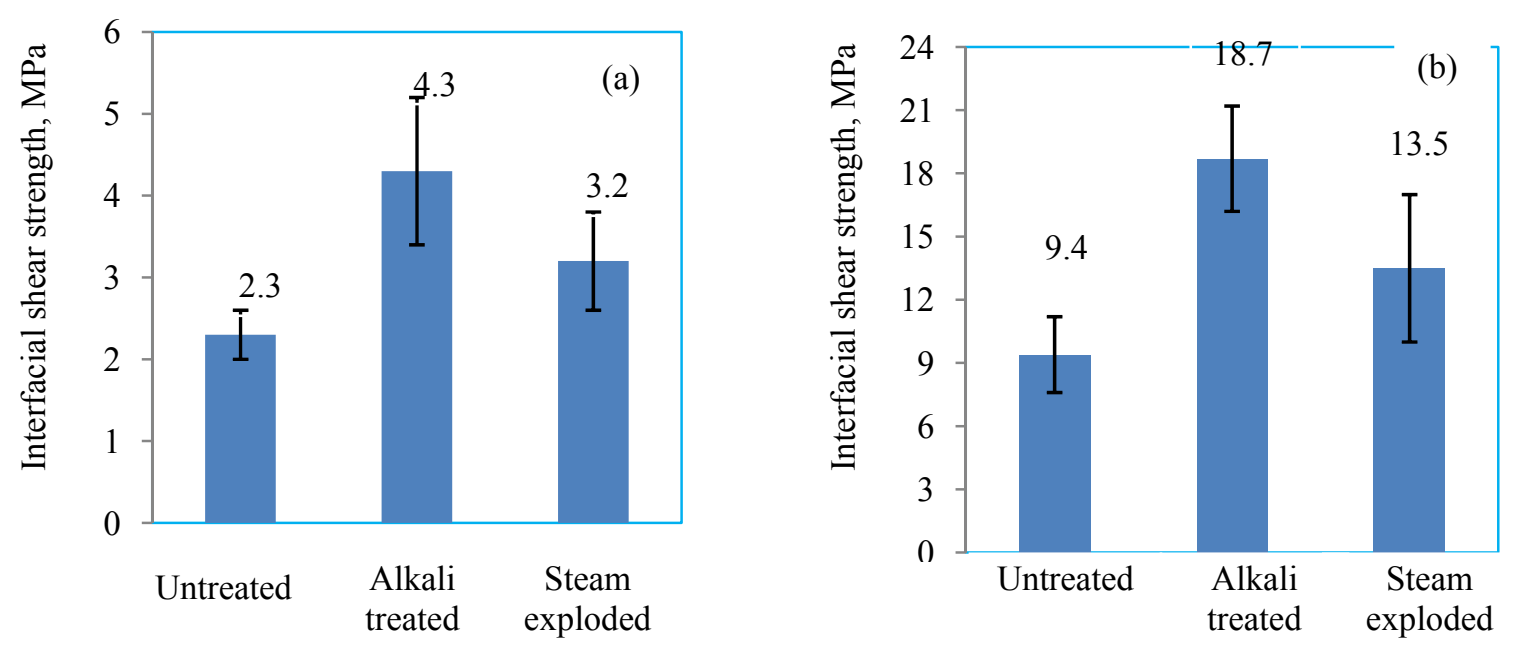

Figure 7. Interfacial shear strength of bamboo fiber bundles and polypropylene (a), unsaturated polyester resin (b)

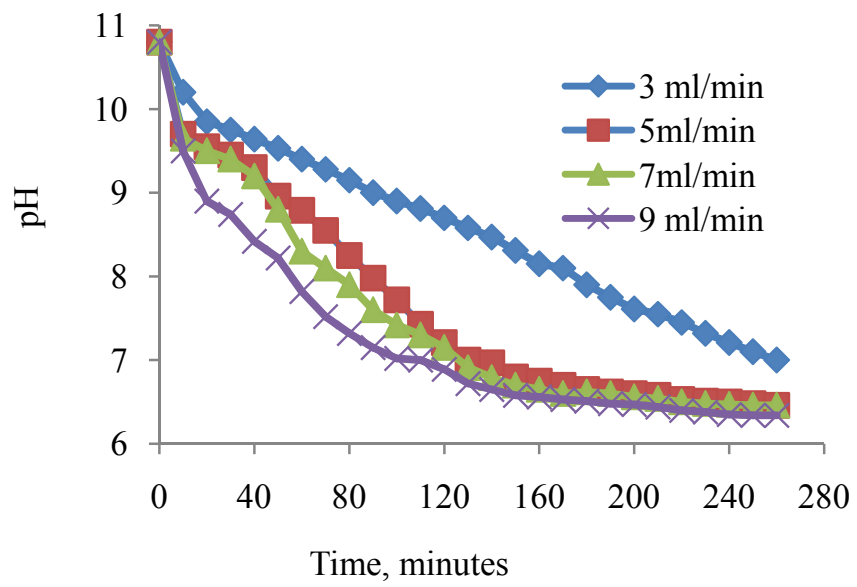

Figure 8 . Change in $\mathrm{pH}$ with various flow rate
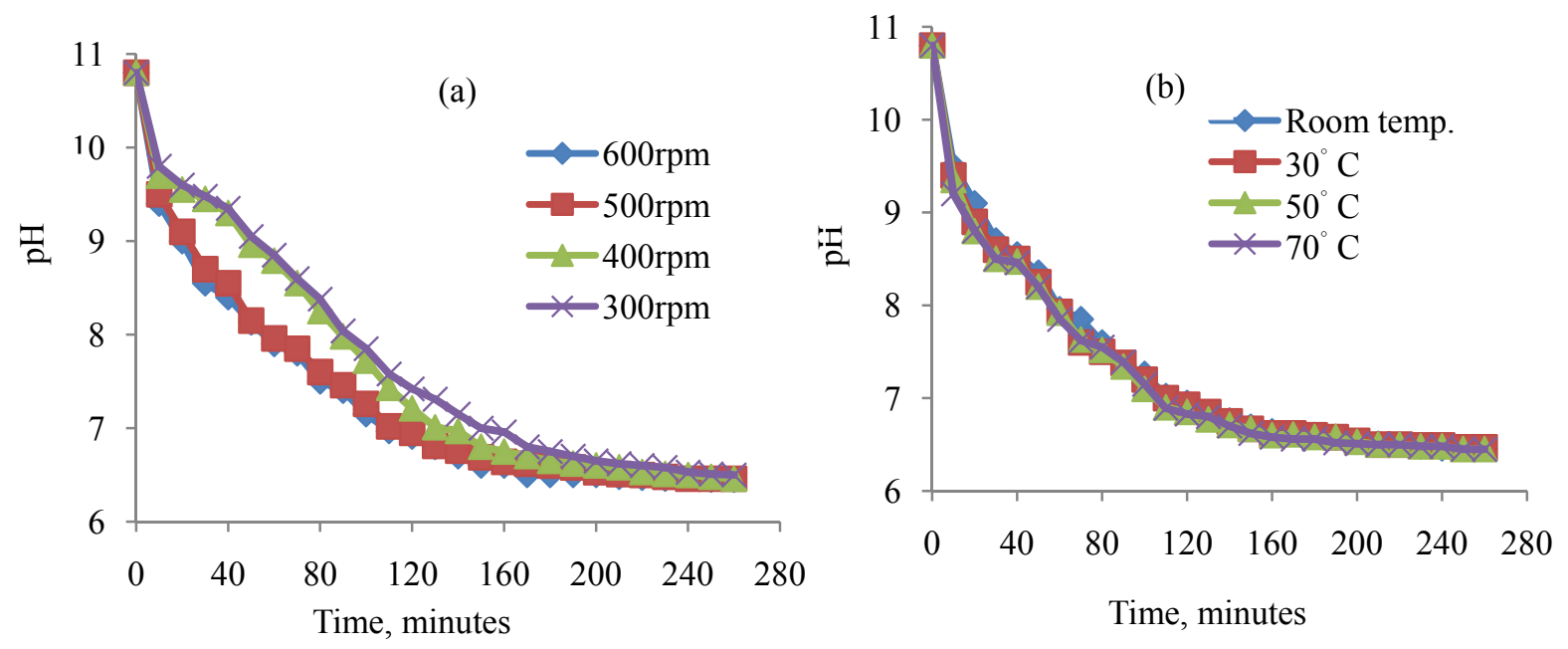

Figure 9. Change in $\mathrm{pH}$ with various stirring speed (a) and reaction temperature (b) 